\title{
STUDY ON PROCESS OF ROTATIONALLY MOLDED TRUCK FENDER AND EFFECT OF TECHNICS ON PRODUCT PROPERTIES
}

\author{
${ }^{1}$ Liu Ya-mei, ${ }^{2}$ Liu Jing, ${ }^{3}$ Liyongpan, ${ }^{4}$ Chengxianming \\ $\left({ }^{1,2}\right.$ Changchun University of Technology,Jilin,Changchun,130012 \\ ${ }^{3}$ Technical Center of Great Wall Motor Co., Ltd. Automotive Engineering Technology Research \\ Center, Baoding City Hebei Province China \\ ${ }^{4}$ Meters kang environmental technology co., LTD., mianyang city, sichuan province, 622700 )
}

Key words: Truck fender; Rotational molding; Impact strength; Melt flow index; Bubble

\begin{abstract}
In this paper,we studied a process for the rotationally molded truck fender . The part's impact strength, the melt flow index and bubbles inside the part are all affected by the heating temperature and time, all of which are analyzed. Finally, the optimized process conditions were given. The result can be a guide for the moulding process and industrialization of product.
\end{abstract}

\section{Introduction}

Rotomolding technology has widespread application in developed countries in Europe, America, Japan and other countries, rotomolding has become one of the major plastic processing technology.In recent years, especially has a continuously development in $10 \% \sim 15 \%$ annual growth rate ${ }^{[1]}$..

Roll forming process of high temperature and long molding cycle have a great influence on mechanical properties especially on the strength performance. Therefore, considering the truck fender use function requirements, studies its performance, especially the impact strength $^{[2]}$.We studied the truck fender roll forming process and the heating temperature and heating time on the properties of plastic molding products in this article, including the impact strength, melt flow index of sample and internal bubble distribution products.Based on the comprehensive studies of the above, optimized the best process conditions, a better control performance. in truck fender was realized with molding.

\section{Truck fender roll forming process research}

\subsection{Truck fender rolling forming products design}

Roll forming products design principles:

1) wall thickness and uniformity: the most important factor in products design is to determine the reasonable thickness, guarantee the uniformity of wall thickness, linear low density polyethylene can provide a wide range of wall thickness $(1.5 \sim 13.0 \mathrm{~mm})$, can meet the requirements of the products the average thickness of $6 \mathrm{~mm}$, and can guarantee the uniformity of wall thickness of the finished products ${ }^{[3]}$.

2) close parallel wall design: according to sidewall design principle, the minimum distance parallel to the wall must be at five times to the average wall thickness, the minimum distance between parallel to the wall is $30 \mathrm{~mm}$, can meet the requirements of molding.

3) the design of the stiffener: this products has reached the wall thickness, strength and comprehensive coordination costs through strengthening design.According to the shape and use requirements combined hollow stiffener and solid to strengthen their respective advantages, products distributed seven hollow stiffener and a solid reinforcement. 
4) deformation control: this product is belong to large curved surface product, but because of the design adopted the design of stiffener and close parallel wall, uniform distribution and products overall thickness, so it can better resistance to deformation.

5) draft design: slope makes the demoulding operation more conveniet, then lowering the cost of plastic products.Due to the shrinkage in cooling from the cavity, easy to emerge, so four hollows reinforced the need around $2^{\circ} \mathrm{draft}$.

6) surface treatment: in view of the application requirements, this product does not require too sophisticated surface treatment, only simple mold polishing.

According to this article research content of roll forming truck fender stamping photos as shown in figure 1 .

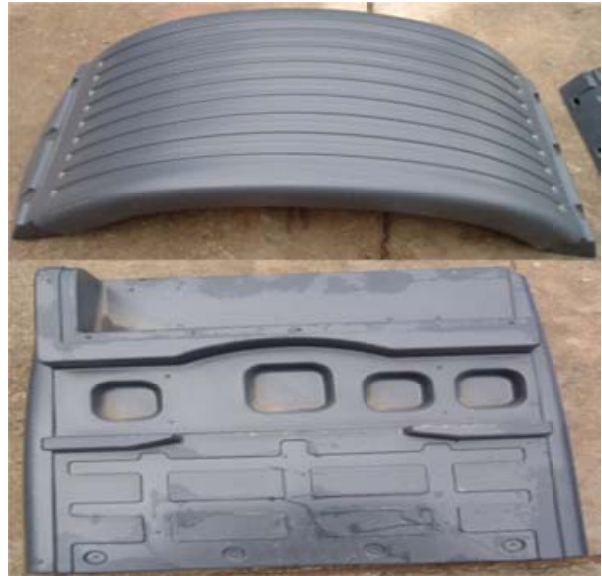

Fig.1 the picture of truck fender

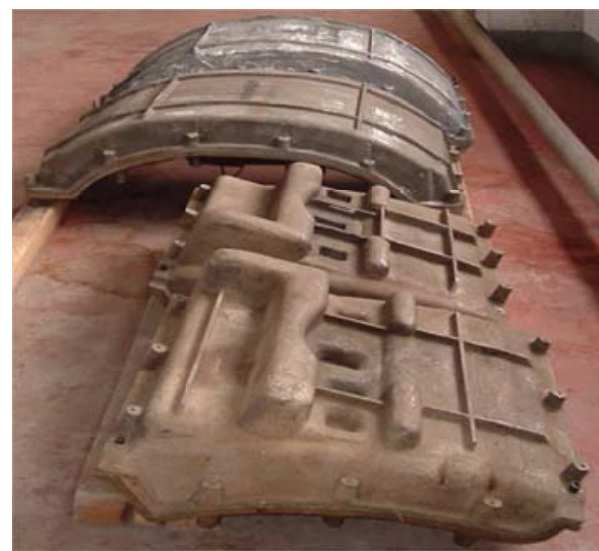

Fig.2 the mold photo for truck fender

\subsection{Truck fender roll forming die design}

This product use the aluminum mould.And in accordance with the requirements of parts, determine the parting surface, clamp, insert, and the characteristics of the special structure design.

1) the determination of parting surface: according to the requirements of products, we should choose maximize products base diameter as the parting surface, and structure for the plane with a steel pin.The parting surface overflow in the process of loading is easy to keep the surface clean when resin.

2) fixture selection: the mold uses bolt fixture.

3) insert: because products applied of reinforcement to increase the thickness of the products in the design, resistance to deformation, so the formation of the deep groove area will produce heat transfer difference, material deposition.In this case, we use the heat transfer performance of good material insert, installed in the mold ${ }^{[4]}$.

4) special structure: in the product structure, deep cavity or muscle to form the heat transfer in mould "dead center", the air little flowor even not flow, The convection around gas inhibits hot air into it.So in the mold surface built a structure, in order to make the surface can produce faster air flow.

Through the study designed mould as shown in figure 2.

\subsection{Truck fender roll forming process conditions}

The stamping forming process consist of feeding, heating, cooling and demoulding and post-treatment of several basic working procedure.Process conditions mainly consider the following principle: 
1)the selection of mold release: in the process of roll forming, plastic powder of heating and the subsequent melting occurred in the mould plastic interface, so it is necessary to use demoulding in inner surface agent to stop the plastic mold and die bonding.

2)rotation speed control: the shaft speed usually control in $5 \sim 25 \mathrm{r} / \mathrm{min}$.Roll-plastic equipment using two adjustable motor provide power with main shaft and the auxiliary shaft respectively, so the rotating speed of main shaft and the auxiliary shaft can be independent regulation. The product shape main shaft speed ratio is 1:3.

3) heating temperature and heating time, heating equipment of the heating chamber temperature range is $250 \sim 400{ }^{\circ} \mathrm{C}$, usually heating time is $10 \sim 40 \mathrm{~min}$.

4)process conditions optimization: in roll forming process, heating temperature, heating time, the main auxiliary shaft speed ratio, cooling methods are the main factors influencing the product performance .

\section{Truck fender roll forming process conditions affect the performance of products}

\subsection{Test equipment and materials}

This test we use the RS - 2600 three arm type rolling machine for five station, heating medium is liquefied petroleum gas .

Experimental materials for linear low density polyethylene plastic resin for special purpose, the main performance indicators: density $\quad 0.935 \mathrm{~g} / \mathrm{cm}^{3}$, melt flow index $4.0 \mathrm{~g} / 10 \mathrm{~min}, 13 \mathrm{mpa}$ tensile strength, impact strength $753.3 \mathrm{~J} / \mathrm{m}$.

\subsection{Test conditions and results of discussion}

Test condition: the heating temperature is $250{ }^{\circ} \mathrm{C} \sim 370{ }^{\circ} \mathrm{C}$, the range of heating time is $10 \sim 40$ min, cooling time is $8 \mathrm{~min}$, in the cold water mist spray cooling conditions.

Impact test samples cut from the roll forming truck fender products, $120 \mathrm{~mm}$ long, $12 \mathrm{~mm}$ wide, $6 \mathrm{~mm}$ thick. Test instrument is impact test apparatus, test types is stretch.Impact velocity 2.5 $\mathrm{m} / \mathrm{s}$, impact energy $13.8 \mathrm{~J}$, test temperature $20{ }^{\circ} \mathrm{C}$ to $-20{ }^{\circ} \mathrm{C}$.Cut a sophisticated $0.25 \mathrm{~mm}$ wide, deep $2.5 \mathrm{~mm}$ gap on the impact direction of each sample.

The following results are five sample average. Table 1 and table 2 respectively show impact test results in the condition of $20{ }^{\circ} \mathrm{C}$ to $-20{ }^{\circ} \mathrm{C}$ under the truck fender, the data curve as shown in figure 3 and figure 4 .

Tab.1 Impact strength of truck fender at $20^{\circ} \mathrm{C}$

\begin{tabular}{|c|r|c|c|c|}
\hline Temperature $\left({ }^{\circ} \mathrm{C}\right)$ & 250 & 290 & 330 & 370 \\
\hline Time (min) & \multicolumn{4}{|c|}{$\begin{array}{l}\text { Impact strength } \\
\left(\mathrm{KJ} / \mathrm{m}^{2}\right)\end{array}$} \\
\hline 10 & - & 83 & 80 & 90 \\
15 & 8 & 102 & 109 & 116 \\
20 & 8 & 116 & 135 & 138 \\
25 & 98 & 127 & 170 & 176 \\
30 & 106 & 238 & 201 & 212 \\
35 & 132 & 211 & 229 & 185 \\
40 & 133 & 184 & 206 & - \\
\hline
\end{tabular}


Tab.2 Impact strength of truck fender at $-20^{\circ} \mathrm{C}$

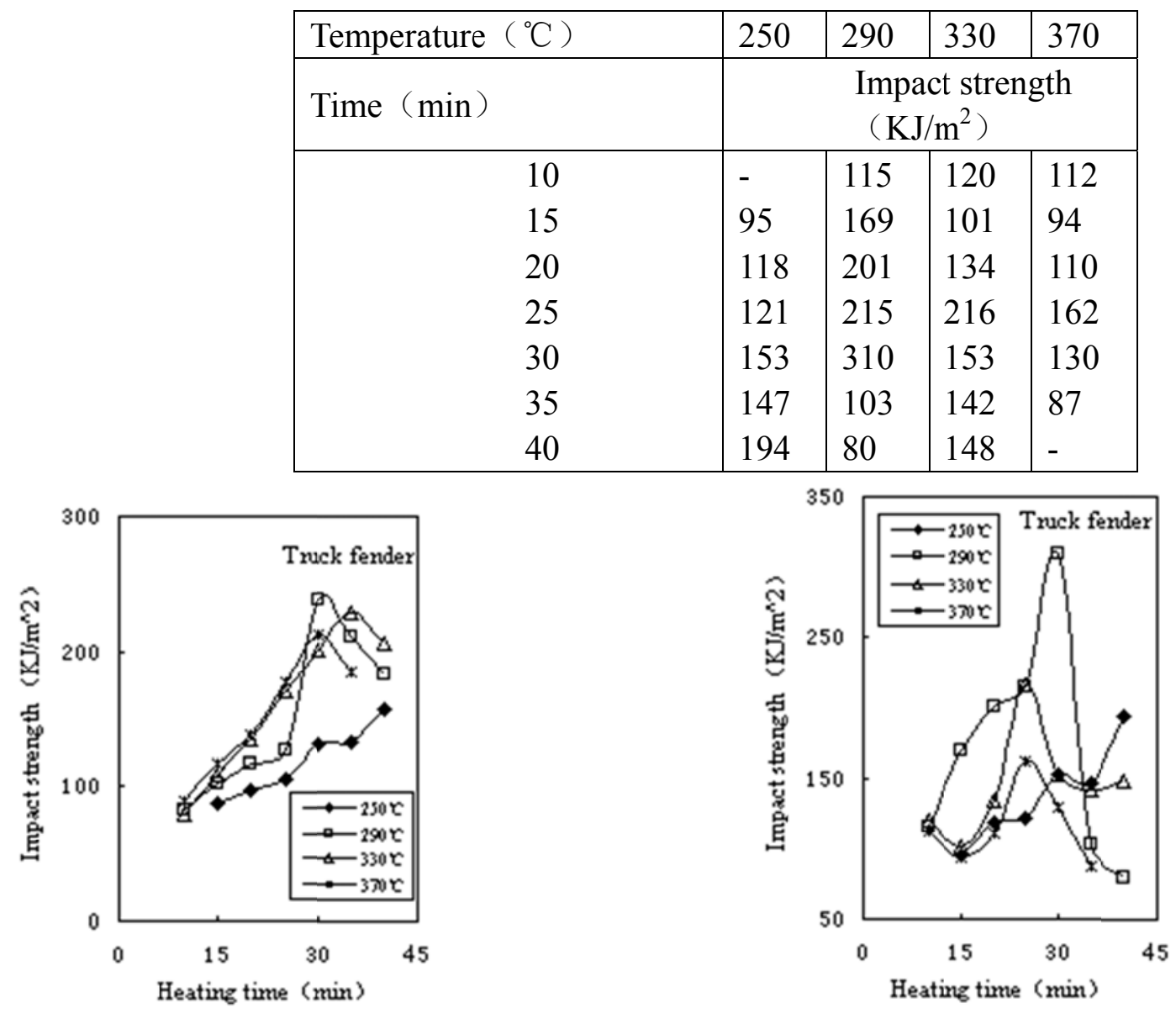

Fig.3 Impact strength versus heating time at $20^{\circ} \mathrm{C}$ for different oven temperatures

Fig.4 Impact strength versus heating time at $-20^{\circ} \mathrm{C}$ for different oven temperatures

As can be seen from figure 3, in a certain temperature range, the impact strength steady rise at room temperature with the increase heating temperature. In figure 4, the maximum impact strength all appeared for each selected furnace temperature, and the furnace temperature increase, when the temperature exceeds $290{ }^{\circ} \mathrm{C}$ the impact strength began to decline due to there have a close relationship between the impact strength and surface oxide layer. Tests show that the sample surface to remove, impact strength will return to their original level.

Sampling from the above mentioned product,study the relationship between the melt flow index (MFI) and the impact strength of the.Tables 3 and 4 respectively show the result of truck fender cross section and inner surface, data curve as shown in figure 5 and figure 6.

Under the condition of longer heating time we can see from the figure $5 \mathrm{MFI}$ and low temperature impact strength decline is proportional.At $250{ }^{\circ} \mathrm{C}$, MFI did not significantly reduce, at $290{ }^{\circ} \mathrm{C}, 330{ }^{\circ} \mathrm{C}$ and $370{ }^{\circ} \mathrm{C}$, , MFI remained stable when the heating time is short. With the extension of heating time, the MFI declined obviously.Compared with figure 4 can be seen MFI decrease before impact strength decrease ${ }^{[5]}$.

In the experiment of inner surface in truck fender, with the extension of heating time, the MFI rapidly reduced to zero, then just corresponds to the low temperature and impact strength reached maximum, this comparison can be seen from figure 6 and figure 4.Because the surface of oxidation, crosslinking the inner surface of MFI falling too fast,then produced a brittle surface. 
Tab.3 The MFI result in the cross-section of truck fender

\begin{tabular}{|c|l|l|l|l|l|}
\hline Temperature $\left({ }^{\circ} \mathrm{C}\right)$ & 250 & 290 & 330 & 370 \\
\hline Time $(\mathrm{min})$ & \multicolumn{4}{|c|}{$\begin{array}{c}\text { Cross section MFI } \\
(\mathrm{g} / 10 \mathrm{~min})\end{array}$} \\
\hline 10 & - & 2.78 & 3.75 & 3.29 \\
15 & 2.21 & 2.85 & 3.67 & 3.44 \\
20 & 2.42 & 3.18 & 3.32 & 3.00 \\
25 & 2.15 & 2.47 & 2.70 & 2.32 \\
30 & 2.44 & 2.00 & 2.40 & 2.05 \\
35 & 2.34 & 1.86 & 2.15 & - \\
40 & 2.23 & 1.39 & - & - \\
\hline
\end{tabular}

Tab.4 The MFI result in the inside surface of truck fender

\begin{tabular}{|c|l|l|l|l|}
\hline Temperature $\left({ }^{\circ} \mathrm{C}\right)$ & 250 & 290 & 330 & 370 \\
\hline Time $(\mathrm{min})$ & \multicolumn{4}{|c|}{ Inside surface MFI } \\
& \multicolumn{4}{|c|}{$/ 10 \mathrm{~min})$} \\
\hline 10 & - & 2.45 & 3.60 & 3.14 \\
15 & - & 2.37 & 3.48 & 0.82 \\
20 & 2.40 & 0.60 & 0.16 & 0.15 \\
25 & 0.11 & 0.12 & 0.00 & 0.00 \\
30 & 0.00 & 0.00 & 0.00 & 0.00 \\
\hline
\end{tabular}
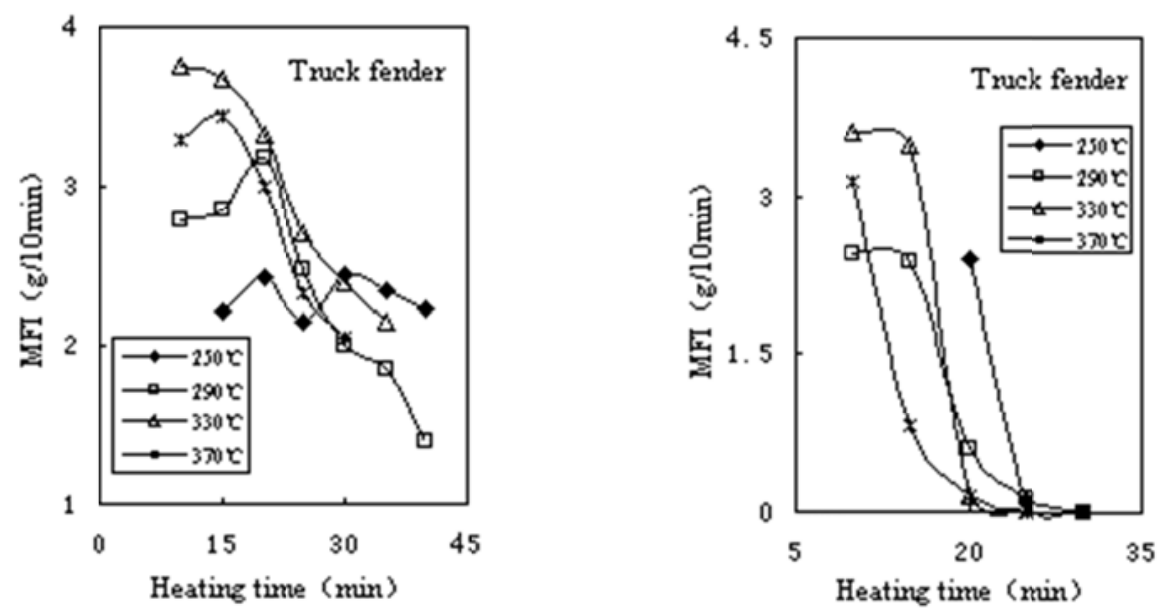

Fig.5 MFI in the cross-section versus heating time for different oven temperatures

Fig.6 MFI in the inside surface versus heating time for different oven temperatures

\section{Conclusion}

Based on the above experimental study on truck fender rolling forming on the impact of process conditions on product performance, we draw the following conclusion:

(1) roll forming the impact strength of truck fender has much to do with the process conditions.In a certain range, it is important to improve truck fender impact performance by increase the heating temperature or longer heating time.

(2) We can conclude a direct relationship between MFI and the impact strength by measure the truck fender cross section and inner surface of MFI,and it can be used to a index of impact strength in products . 
(3) In the case of high temperature heating or extension of the heating time, truck fender inner surface material of MFI rapidly reduced to zero, corresponds to the low temperature impact strength reached maximum, then rapidly reduce.

\section{References}

[1]Rahner S. The last trend: rotational moulding. Kunststoffe Plast Europe[J], 1998, 88(1): 6 9 [2]A G Spence and R J Crawford. The Effect of Processing Variables on the Formation and Removal of Bubbles in Rotationally Molded Products. Polymer Engineering and Science[J], 1996, 36(7): $993 \sim 1009$

[3]George Gogos. Bubble removal in rotational molding. Polymer Engineering and Science[J], 2004, 44(2): 388 394

[4]Lim K K, Lanakiev A, Hull J B. Numerical modelling for rotational moulding with non-isothermal heating. Plastics, Rubber and Composites[J], 2003, 32(10): 421 430

[5]Liu S J, Lai C C, Lin S T. Optimizing the Impact Strength of Rotationally Molded Parts. Polymer Engineering and Science[J], 2000, 40(2): 473 480 